\title{
Comment on "Review of Case Narratives from Fatal Overdoses Associated with Injectable Naltrexone for Opioid Dependence"
}

\author{
Bernard Silverman ${ }^{1}\left[0\right.$. Gary Bloomgren ${ }^{1} \cdot$ Priya Jain $^{1} \cdot$ Kimberley Marcopul $^{1} \cdot$ Alexandra Silveira $^{1}$. \\ James Fratantonio $^{1} \cdot$ Maria Sullivan $^{1,2} \cdot$ Sarah Akerman ${ }^{1}$
}

Published online: 28 June 2018

(c) The Author(s) 2018

\section{Dear Editor}

Here, we raise concerns regarding the methodology used and conclusions reached in a recent publication by Saucier et al. [1] that retrospectively evaluated cases of spontaneously reported opioid overdose in patients treated with extendedrelease injectable naltrexone (XR-NTX; VIVITROL ${ }^{\circledR}$ ) using a US FDA dataset. We concentrate on some specific points, but other concerns include failure to cite published data related to longer-term use of XR-NTX [2, 3], citations of media articles, and the funding of this study by a nonscientific advocacy organization [1].

Post-marketing safety surveillance is a public health imperative, and Alkermes adheres to rigorous FDA standards regarding the collection, follow-up, and submission of spontaneous case reports for all marketed Alkermes products, including VIVITROL. The most recent Alkermes review of cumulative post-marketing safety data submitted to the FDA (April 2017) evaluated $>360,000$ patients treated with XR-NTX and included the data evaluated by Saucier et al. [1]. This review did not demonstrate an increased risk of opioid overdose, including fatal overdose, either on treatment with XR-NTX or within 2 months of discontinuation, as implied by Saucier et al. [1].

This comment refers to the article available at https://doi. org/10.1007/s40264-018-0653-3.

An author's reply to this comment is available at https://doi. org/10.1007/s40264-018-0692-9.

Bernard Silverman

bernard.silverman@alkermes.com

Sarah Akerman

Sarah.Akerman@alkermes.com

1 Alkermes, Inc, Waltham, MA, USA

2 Clinical Psychiatry, Columbia University, New York, NY, USA
Saucier et al. [1] assert the potential presence of a biologic "rebound effect" following XR-NTX discontinuation (i.e., increased susceptibility to overdose as a result of XR-NTX treatment) [1]. While animal model data have suggested that chronic naltrexone exposure may lead to an upregulation of opioid receptors in the mouse central nervous system [4, 5], there is no evidence that the data from animal models translate to an increased risk of overdose as evidenced by human laboratory data $[6,7]$ or clinical trial adverse events [2, 8-13]. Lee et al. [13], who recently reported the results of a National Institute on Drug Abuse (NIDA)-sponsored trial $(n=570)$ comparing the effectiveness of XR-NTX and buprenorphine-naloxone (BUP-NX), stated, "So far, no large trial has given a clear signal that XR-NTX treatment increases overdose events or death compared with placebo treatment, treatment as usual, and now BUP-NX treatment." [13].

We have a number of concerns regarding the methodology used in the analysis. The authors assumed that an "overdose" event was an "opioid overdose" even when the case information regarding the $\operatorname{drug}(\mathrm{s})$ taken was missing or unclear [1]. Applying such adjudication assumptions to missing or incomplete data, which are prevalent in spontaneously reported data, can lead to case misclassification and affect the validity of any conclusions. If such imputation/ adjudication methods are used, a sensitivity analysis should be performed in which only cases with clear evidence of stated opioid overdose are used to verify any such conclusion. The authors also took liberties in applying assumptions in their conclusions beyond what was supported by the data. Event latency from the last dose of drug was only known for $28(54 \%)$ of the 52 case reports, yet the authors apply this time course to all 52 events [1].

There are additional incomplete interpretations of the literature. In describing the comparative effectiveness trial by Lee et al. [13], Saucier et al. [1] state that “... a randomized trial had 15 participants who had overdoses 
(two of which were fatal) in the Vivitrol group ( $n=283$ participants; $n=204$ per-protocol group), and eight overdoses (three fatal) in the buprenorphine group $(n=287$; $n=270$ per-protocol group)." It should be noted that some patients within this study had multiple overdoses, and 8 of 18 overdose events in the XR-NTX group were in patients who never received XR-NTX [13]. The authors further cite an absence of statistical analyses regarding these overdose rates but omit relevant statements from the manuscript [1]. Lee et al. [13] state that, while the study was not powered to detect significant differences in overdose, there was no difference in the rate of overdose events between groups and further observed that "most overdose events occurred at times quite distal to the last dose of study medication ... or to discharge from detoxification." Lee et al. [13] also note, "This outcome makes it difficult to attribute an association between study medication and overdose."

Similarly, Saucier et al. [1] offer an incomplete interpretation from a study comparing outcomes on methadone, buprenorphine, and a naltrexone implant [14]. The authors state that the risk of fatal overdose did not differ among groups [1] but omit the following related result: "rates of non-fatal opioid poisoning were significantly lower in naltrexone-treated patients than in methadone-treated patients following treatment $(p<0.001)$." [14].

Saucier et al. [1] make reference to the XR-NTX registry (NCT01422837) and state that "Alkermes has not yet made the results public." [1]. In fact, the registry data $(N=395)$ have been previously presented at scientific conferences [15-17], and a manuscript has been published [3]. In this registry, three overdose deaths were reported, which occurred 20 days, 2 , and 4 months post-last dose [3]. It is important to note that these registry case reports were also reported to the FDA and are therefore already included in the dataset analyzed by Saucier et al. [1]. The authors also incorrectly asserted that Alkermes engages in "the highly unusual marketing practice of mailing starting doses to patients." Alkermes does not mail VIVITROL doses directly to patients; VIVITROL must be prepared and administered by a healthcare provider [18].

According to the Centers for Disease Control and Prevention (CDC), opioid overdose deaths occurred in 13 per 100,000 people in the USA in 2016 , and this rate is increasing [19]. It is imperative that patients and providers have scientifically accurate information to inform individual treatment decisions. Ongoing efforts to improve access to pharmacological treatments for opioid use disorder and to advance research on the known issue of treatment retention for all FDA-approved medications used in the treatment of opioid use disorder are critical to addressing this epidemic [20-23].

\section{Compliance with Ethical Standards}

Conflict of interest Bernard Silverman, Gary Bloomgren, Priya Jain, Kimberley Marcopul, Alexandra Silveira, James Fratantonio, Maria Sullivan, Sarah Akerman are all employees and shareholders of Alkermes, Inc.

Funding This letter was funded by Alkermes, Inc.

Open Access This article is distributed under the terms of the Creative Commons Attribution-NonCommercial 4.0 International License (http://creativecommons.org/licenses/by-nc/4.0/), which permits any noncommercial use, distribution, and reproduction in any medium, provided you give appropriate credit to the original author(s) and the source, provide a link to the Creative Commons license, and indicate if changes were made.

\section{References}

1. Saucier R, Wolfe D, Dasgupta N. Review of case narratives from fatal overdoses associated with injectable naltrexone for opioid dependence. Drug Saf. 2018. https://doi.org/10.1007/s4026 4-018-0653-3.

2. Earley PH, Zummo J, Memisoglu A, Silverman BL, Gastfriend DR. Open-label study of injectable extended-release naltrexone (XR-NTX) in healthcare professionals with opioid dependence. J Addict Med. 2017;11(3):224-30.

3. Saxon AJ, Akerman SC, Liu CC, Sullivan MA, Silverman BL, Vocci FJ. Extended-release naltrexone (XR-NTX) for opioid use disorder in clinical practice: vivitrol's cost and treatment outcomes registry. Addiction. 2018. https://doi.org/10.1111/ add.14199.

4. Sirohi S, Kumar P, Yoburn BC. Mu-opioid receptor up-regulation and functional supersensitivity are independent of antagonist efficacy. J Pharmacol Exp Ther. 2007;323(2):701-7.

5. Bardo MT, Bhatnagar RK, Gebhart GF. Chronic naltrexone increases opiate binding in brain and produces supersensitivity to morphine in the locus coeruleus of the rat. Brain Res. 1983;289(1-2):223-34.

6. Cornish JW, Henson D, Levine S, Volpicelli J, Inturrisi CE, Yoburn BC, O'Brien CP. Naltrexone maintenance: effect on morphine sensitivity in normal volunteers. Am J Addict. 1993;2(1):34-8.

7. Arnold-Reed DE, Hulse GK, Hansson RC, Murray SD, O'Neil $\mathrm{G}$, Basso MR, et al. Blood morphine levels in naltrexone-exposed compared to non-naltrexone-exposed fatal heroin overdoses. Addict Biol. 2003;8(3):343-50.

8. Krupitsky E, Nunes EV, Ling W, Illeperuma A, Gastfriend DR, Silverman BL. Injectable extended-release naltrexone for opioid dependence: a double-blind, placebo-controlled, multicentre randomised trial. Lancet. 2011;377(9776):1506-13.

9. Krupitsky E, Nunes EV, Ling W, Gastfriend DR, Memisoglu A, Silverman BL. Injectable extended-release naltrexone (XR-NTX) for opioid dependence: long-term safety and effectiveness. Addiction. 2013;108(9):1628-37.

10. Kampman K, Gromov I, Sirota A, Silverman B, Qiao X, Gastfriend DR. Long-term safety and tolerability of extended-release naltrexone in alcohol and/or opioid-dependent patients: a randomized, active-controlled study. In: American Psychiatric Association annual meeting; May 3-8, 2008; Boston, MA.

11. Lee JD, Friedmann PD, Kinlock TW, Nunes EV, Boney TY, Hoskinson RA Jr, et al. Extended-release naltrexone to prevent 
opioid relapse in criminal justice offenders. N Engl J Med. 2016;374(13):1232-42.

12. Tanum L, Solli KK, Latif ZE, Benth JS, Opheim A, SharmaHaase K, et al. Effectiveness of injectable extended-release naltrexone vs daily buprenorphine-naloxone for opioid dependence: a randomized clinical noninferiority trial. JAMA Psychiatry. 2017;74(12):1197-205.

13. Lee JD, Nunes EV Jr, Novo P, Bachrach K, Bailey GL, Bhatt S, et al. Comparative effectiveness of extended-release naltrexone versus buprenorphine-naloxone for opioid relapse prevention (X:BOT): a multicentre, open-label, randomised controlled trial. Lancet. 2018;391(10118):309-18.

14. Kelty E, Hulse G. Fatal and non-fatal opioid overdose in opioid dependent patients treated with methadone, buprenorphine or implant naltrexone. Int J Drug Policy. 2017;46:54-60.

15. Capote HA, Zummo J, Memisoglu A, Lu M, Rainka M, Silverman BL. Substance use and employment outcomes among patients initiating extended-release naltrexone (XR-NTX): real-world data from the XR-NTX opioid dependence registry. (ISPOR) International Society for Pharmacoeconomics Outcomes Research; 2014 May 31-June 4; Montreal, Canada.

16. Silverman BL, Gastfriend DR. Safety and effectiveness of treatment with a once-monthly, injectable formulation of naltrexone (XR-NTX) in a real-world clinical practice setting. Philadelphia: American Psychiatric Association (APA); 2012.
17. Zummo J, Lu M, Wilson P, Memisoglu A, Silverman BL, Doshi JA. Substance use and healthcare resource utilization patterns among patients initiating extended-release naltrexone (XR-NTX): real world data from the XR-NTX opioid dependence registry. Boston: Academy of Managed Care Pharmacy (ACMP); 2014.

18. Alkermes Inc. VIVITROL ${ }^{\circledR}$ (Prescribing Information). Waltham, MA; 2015. https://www.accessdata.fda.gov/drugsatfda_docs/label /2015/021897s029lbl.pdf. Accessed 20 June 2018.

19. Hedegaard H, Warner M, Minino AM. Drug overdose deaths in the United States, 1999-2016. NCHS data brief, no 294. Hyattsville: National Center for Health Statistics; 2017.

20. Volkow ND. Medications for opioid use disorder: bridging the gap in care. Lancet. 2018;391(10118):285-7.

21. Volkow ND, Frieden TR, Hyde PS, Cha SS. Medication-assisted therapies-tackling the opioid-overdose epidemic. N Engl J Med. 2014;370(22):2063-6.

22. Lott DC. Extended-release naltrexone: good but not a panacea. Lancet. 2018;391(10118):283-4.

23. Morgan JR, Schackman BR, Leff JA, Linas BP, Walley AY. Injectable naltrexone, oral naltrexone, and buprenorphine utilization and discontinuation among individuals treated for opioid use disorder in a United States commercially insured population. J Subst Abuse Treat. 2018;85:90-6. 